\title{
Gene expression profiling of anti-CTLA4-treated metastatic melanoma in patients with treatment-induced autoimmunity
}

\author{
Scott C Bresler ${ }^{1,2}$, Le Min ${ }^{2,3}$, Scott J Rodig ${ }^{1,2}$, Andrew C Walls ${ }^{2,4}$, Shuyun Xu1,2, Songmei Geng ${ }^{1,2}$, F Stephen Hodi ${ }^{2,5}$, \\ George F Murphy ${ }^{1,2}$ and Christine G Lian ${ }^{1,2}$
}

Ipilimumab (IPI) is a monoclonal antibody that targets the inhibitory CTLA4 receptor of T cells, enhancing T-cell-driven antitumor responses. IPI therapy in metastatic melanoma results in significant improvement in disease-free and overall survival, although after initial responses disease progression generally ensues. Identification of specific responses in tissue where melanoma tumor cells are subjected to IPI-driven immune attack may reveal mechanisms of treatment efficacy or resistance, permitting refinement of targeted therapeutic approaches. We used NanoString digital barcoding chemistry to identify changes in the transcriptome of metastatic melanoma cells before and after IPI treatment using two comprehensive panels containing a total of 1330 unique genes. Only patients who developed autoimmune disorders following treatment, signifying a robust immune response, were included. Despite evidence of an enhanced immune response, most patients eventually exhibited disease progression. Overall, data from five pre-IPI tumors and four post-IPI tumor samples (from three patients) permitted identification of several candidate genes that showed increased expression based on normalized counts after therapy. These included $T T K(\sim 3.1$-fold, $P=1.18 \mathrm{e}-4)$, which encodes a dual-specificity protein tyrosine kinase, a known cell cycle regulator, and BIRC5 ( 3.0-fold, $P=9.36 \mathrm{e}-4)$, which encodes the antiapoptotic protein survivin. Both TTK (MPS1) and survivin are targetable proteins against which a number of pharmacologic agents have been developed. CDK1, which encodes a protein tyrosine kinase known to phosphorylate survivin, was also upregulated $(\sim 3.2$-fold, $P=2.80-3)$. Tumor cell expression of $T$ TK and survivin proteins was confirmed using immunohistochemistry in an expanded patient cohort. Differences in gene expression for several commonly encountered immune antigens, such as CD3, CD4, CD8, and CTLA4, were not statistically significant, likely reflecting the long length of time (average 323 days) between the last IPI dose and post-treatment biopsies. Although our sample size is limited, these results for the first time identify targetable genes that are significantly altered by interaction between a highly activated, IPI-treated immune system and melanoma cells.

Laboratory Investigation (2017) 97, 207-216; doi:10.1038/labinvest.2016.126; published online 5 December 2016

Ipilimumab (IPI) is a humanized monoclonal antibody that targets the inhibitory CTLA4 receptor of T cells. ${ }^{1,2}$ Treatment of metastatic melanoma patients with IPI results in improved overall survival, which has led to FDA approval for patients with metastatic or unresectable disease. ${ }^{3}$ However, autoimmune phenomena are significant treatment-related adverse events, and specific reported manifestations include skin and gastrointestinal involvement as well as hypophysitis. ${ }^{3,4}$ Despite substantial patient morbidity and occasional mortality resulting from these phenomena, the development of autoimmune toxicity has been correlated with antimelanoma treatment responses in some ${ }^{5-7}$ but not all clinical trials. ${ }^{3}$ Additionally, the development of autoimmune toxicity has been suggested to be inversely correlated with relapse risk. ${ }^{4}$

IPI appears to act primarily through the activation of both $\mathrm{CD} 4+$ and $\mathrm{CD} 8+\mathrm{T}$ cells, as demonstrated in flow cytometric analysis of the peripheral blood of treated patients. ${ }^{8}$ Furthermore, the expression of intratumoral-specific immune markers such as FOXP3 and IDO before treatment as well as the number of tumor-infiltrating lymphocytes after treatment

\footnotetext{
Program in Dermatopathology, Department of Pathology, Brigham and Women's Hospital, Boston, MA, USA; ${ }^{2}$ Harvard Medical School, Boston, MA, USA; ${ }^{3}$ Endocrinology Division, Department of Medicine, Brigham and Women's Hospital, Boston, MA, USA; ${ }^{4}$ Department of Dermatology, Brigham and Women's Hospital, Boston, MA, USA and ${ }^{5}$ Dana Farber Cancer Institute, Boston, MA, USA

Correspondence: Dr CG Lian MD, Program in Dermatopathology, Department of Pathology, Brigham and Women's Hospital, 221 Longwood Avenue, EBRC Suite 401, Boston, MA 02115 USA.

E-mail: cglian@bwh.harvard.edu

Received 1 July 2016; revised 17 October 2016; accepted 28 October 2016
} 
both appear to be correlated with clinical response. ${ }^{9}$ Combinatorial strategies have also shown promise, as we have recently demonstrated in patients where IPI in combination with vascular endothelial growth factor inhibition by bevacizumab enhances intratumoral CD8 and macrophage infiltration as well as endothelial activation. ${ }^{10}$ Although studies correlating the antitumor response to autoimmunity-involved tissues are limited, T-cell clones generated by IPI therapy that are directed against common antigens, such as Melan-A, have been described. ${ }^{11}$

It remains largely unknown as to how precisely melanoma cells respond to or are altered by immune attack elicited by checkpoint blockade strategies. Accordingly, to examine specifically the response of melanoma tumor cells to an IPIactivated immune system, we used NanoString digital barcoding chemistry ${ }^{12}$ to quantitate expression levels of a wide panel of cancer- and immune-related genes before and after therapy in patients who developed clinically significant, IPI-related autoimmune disorders. Although these patients had evidence of an immunological response to treatment, most were unable to mount a sustained antitumor response (Table 1). Accordingly, this small cohort has the potential to provide insight into how melanomas may evolve to resist checkpoint blockade therapy in spite of systemic evidence of an activated cytotoxic immune response in the form of autoimmunity. We identified possible tumor responses at gene expression and immunohistochemical levels with implications that could limit the impact of immune checkpoint inhibition and that are therefore relevant to future combinatorial strategies to enhance therapeutic efficacy.

\section{MATERIALS AND METHODS Patient Population}

This study was approved by the Brigham and Women's Hospital Institutional Review Board. Patients with metastatic melanoma who were treated with IPI were identified, and were subsequently further selected based on development of clinically significant autoimmune disorders that were confirmed by tissue biopsy or serum biochemical measurements, including colitis, dermatitis, and hypophysitis. Twenty-three such patients were identified, and metastatic melanoma specimens from these patients obtained before and after treatment with IPI were sought from the archives of the Brigham and Women's Hospital Department of Pathology. Four patients with paired biopsies before and after treatment that developed IPI-related autoimmune disorders (all with clinically confirmed hypophysitis, one also with biopsyproven colitis and one with hepatitis), indicating a robustly activated immune system (Table 1). One patient had two biopsies after treatment. Furthermore, an additional pretreatment biopsy was added from a fifth patient with autoimmune hepatitis, for a total of five tumor biopsies pre-treatment and five biopsies after treatment. All patients received one or several courses of steroids after the development of autoimmune toxicities (Table 1). In terms of response to IPI therapy, three patients experienced disease progression, and one patient exhibited stable disease. Three of five patients had evidence of an initial partial radiologic response to treatment. The average time to biopsy after IPI treatment was 323 days (range 41-610 days). For immunohistochemical studies to confirm the NanoString findings at a protein level, we evaluated an expanded patient cohort (total $n=10$; the additional five patients in the expanded cohort are denoted in Supplementary Table S1). The average age of all 10 patients was 59 years, with an average time to biopsy of 335 days (range 145-614 days). Two of five patients in the expanded cohort had evidence of an initial radiologic response to IPI.

\section{NanoString Analysis}

Two commercially available 770-gene panels (PanCancer Pathways and PanCancer Immune) containing 1330 unique genes (available at www.nanostring.com), including 40 housekeeping genes and six positive controls each were used (Nanostring Technologies, Seattle, WA, USA). PanCancer Pathways contains 606 pathway genes as well as 124 cancerdriven genes, whereas PanCancer Immune contains 730 immune genes known to be broadly relevant in the cancer immune response. RNA was isolated from $25 \mu \mathrm{m}$ scrolls of formalin-fixed, paraffin embedded metastatic melanoma tissue after deparaffinization using the RNeasy Mini Kit (Qiagen, Hilden, Germany) according to the manufacturer's instructions. RNA concentrations were determined by Nanodrop (Thermo Scientific, Wimington, DE, USA). Reporter and capture probes were hybridized during a $20 \mathrm{~h}$ incubation at $65^{\circ} \mathrm{C}$, and the resulting RNA complexes were subsequently immobilized and counted on an nCounter analyzer (Nanostring technologies, Seattle, WA, USA) according to the manufacturer's instructions.

Raw data were normalized based on the geometric mean of negative controls, internal housekeeping genes, and positive controls in nSolver 2.5. As two post-IPI biopsies from patient $\mathrm{B}$ were analyzed, these data were averaged for further use after normalization. Additionally, low counts were obtained from the post-IPI tumor of patient A, and these data were excluded for analysis. A high degree of correlation was obtained for the 130 genes present in both gene panels $\left(R^{2}=0.942\right.$ for pre-IPI common genes; $R^{2}=0.979$ for post-IPI average counts; Supplementary Figure 1). As correlation was poor for data points below 25 normalized counts (Supplementary Figure 1), genes with counts in this range before or after impilimumab were excluded from further analysis, resulting in an analysis set of 820 unique genes. Normalized counts from genes included in both panels and fulfilling the minimum count requirement were averaged before additional analysis.

$P$-values were calculated from the $\log _{2}$-transformed normalized data using a two-tailed, unpaired Student's $t$-test in Microsoft Excel. 16 genes with a raw $P$-value of $<0.01$ were found. Of these, 12 genes had at least a twofold 
Table 1 Original cohort: patient population and clinical characteristics

\begin{tabular}{|c|c|c|c|c|c|c|c|c|c|}
\hline Patient & Age/sex & $\begin{array}{l}\text { Primary tumor, } \\
\text { depth of invasion, } \\
\text { known molecular } \\
\text { alterations }\end{array}$ & $\begin{array}{l}\text { Stage when receiving } \\
\text { ipilimumab }\end{array}$ & $\begin{array}{l}\text { Ipilimumab } \\
\text { dose/duration }\end{array}$ & $\begin{array}{l}\text { Treatment-related } \\
\text { autoimmune event(s) }\end{array}$ & $\begin{array}{l}\text { Prior/adjuvant } \\
\text { therapies }\end{array}$ & Clinical course & $\begin{array}{l}\text { Tumor before } \\
\text { treatment }\end{array}$ & $\begin{array}{l}\text { Tumor after } \\
\text { treatment }\end{array}$ \\
\hline 1 & $57 \mathrm{~F}$ & $\begin{array}{l}\text { Unknown primary } \\
\text { (BRAF, NRAS, KIT, } \\
\text { PDGFR wild-type) }\end{array}$ & $\begin{array}{l}\text { IV (lung and mediastinal } \\
\text { lymph node metastases) }\end{array}$ & $\begin{array}{l}3 \mathrm{mg} / \mathrm{kg}, 4 \\
\text { cycles }\end{array}$ & $\begin{array}{l}\text { Hypophysitis with central } \\
\text { hypothyroidism, dermatitis, } \\
\text { adrenalitis }\end{array}$ & None & $\begin{array}{l}\text { Initial partial } \\
\text { response, then } \\
\text { progression } \\
\text { (intracranial } \\
\text { metastasis) }\end{array}$ & $\begin{array}{l}\text { Mediastinal } \\
\text { lymph node }\end{array}$ & $\begin{array}{l}391 \text { days after } \\
\text { treatment, right } \\
\text { lower lobe lung } \\
\text { nodule }\end{array}$ \\
\hline 2 & $61 M$ & $\begin{array}{l}\text { Left back (BRAF, } \\
\text { NRAS, KIT wild- } \\
\text { type) }\end{array}$ & $\begin{array}{l}\text { IV (left axilla and lung } \\
\text { metastases) }\end{array}$ & $\begin{array}{l}3 \mathrm{mg} / \mathrm{kg}, 4 \\
\text { cycles }\end{array}$ & $\begin{array}{l}\text { Hypophysitis with central } \\
\text { hypothyroidism and } \\
\text { hypogonadotropic } \\
\text { hypogonadism }\end{array}$ & None & $\begin{array}{l}\text { Stable disease, then } \\
\text { progression }\end{array}$ & $\begin{array}{l}\text { Right lower } \\
\text { lobe lung } \\
\text { nodule }\end{array}$ & $\begin{array}{l}\text { A. } 46 \text { days after } \\
\text { treatment, left } \\
\text { axillary mass } \\
\text { B. } 453 \text { days after } \\
\text { treatment, left } \\
\text { upper arm skin }\end{array}$ \\
\hline 3 & $54 \mathrm{~F}$ & $\begin{array}{l}\text { Upper back, } \\
3.1 \text { mm (BRAF } \\
\text { V600E, NRAS wild- } \\
\text { type) }\end{array}$ & $\begin{array}{l}\text { IV (neck, liver, and brain } \\
\text { metastases) }\end{array}$ & $\begin{array}{l}10 \mathrm{mg} / \mathrm{kg}, 4 \\
\text { cycles }\end{array}$ & $\begin{array}{l}\text { Hypophysitis with central } \\
\text { hypothyroidism, uveitis, and } \\
\text { colitis }\end{array}$ & $\begin{array}{l}\text { Adjuvant vemurafenib } \\
\text { (ipilimumab/ve- } \\
\text { murafenib trial) and } \\
\text { stereotactic brain XRT }\end{array}$ & $\begin{array}{l}\text { Initial partial } \\
\text { response, then } \\
\text { progression }\end{array}$ & Brain mass & $\begin{array}{l}610 \text { days after } \\
\text { treatment, brain } \\
\text { mass }\end{array}$ \\
\hline 4 & $67 \mathrm{~F}$ & $\begin{array}{l}\text { Left Upper Arm. } \\
\text { (BRAF wild-type, } \\
\text { NRAS Q61E) }\end{array}$ & $\begin{array}{l}\text { IV (brain, pancreas, } \\
\text { vertebral bone, and } \\
\text { widespread lymph node } \\
\text { metastases) }\end{array}$ & $\begin{array}{l}3 \text { mg/kg, } 3 \\
\text { cycles }\end{array}$ & $\begin{array}{l}\text { Hepatitis, hypophysitis with } \\
\text { secondary adrenal } \\
\text { insufficiency, and subclinical } \\
\text { hypothyroidism }\end{array}$ & None & Progression & $\begin{array}{l}\text { Left axillary } \\
\text { lymph node }\end{array}$ & $\begin{array}{l}41 \text { days after } \\
\text { treatment, left } \\
\text { axillary lymph } \\
\text { node }\end{array}$ \\
\hline 5 & $70 \mathrm{M}$ & $\begin{array}{l}\text { Right Upper back, } \\
1.38 \mathrm{~mm} \text {, (BRAF } \\
\text { V600K) }\end{array}$ & $\begin{array}{l}\text { IV (multiple subcutaneous, } \\
\text { peritoneal, retroperitoneal, } \\
\text { and mediastinal } \\
\text { metastases) }\end{array}$ & $\begin{array}{l}10 \mathrm{mg} / \mathrm{kg}, 67 \\
\text { cycles }\end{array}$ & Hepatitis & GM-CSF & $\begin{array}{l}\text { Initial partial } \\
\text { response, then } \\
\text { stable disease }\end{array}$ & $\begin{array}{l}\text { Axillary skin } \\
\text { (metastasis) }\end{array}$ & $\begin{array}{l}\text { No tissue } \\
\text { available }\end{array}$ \\
\hline
\end{tabular}

Abbreviations: GM-CSF, granulocyte-macrophage colony-stimulating factor; XRT, X-ray therapy. 
difference in expression before and after IPI. $Z$-scores for individual data points from these 12 genes were calculated $(z=[$ mean-count $] /$ s.d.) using Microsoft Excel, and then were clustered for visual analysis using the tumor samples as an ordered set in RStudio (Figure 1). ${ }^{13}$ Benjamimi-Hochberg $Q$-values were then calculated based on $P$-value rank order with false discovery rates (FDRs) of $0.5,0.4,0.3,0.2$, and 0.1 (Table 2) to correct for multiple hypothesis testing $(\mathrm{Q}=i / n \times \mathrm{FDR}$, where $i$ is the $P$ rank, $n$ is the number of genes assayed, and FDR the false discovery rate). ${ }^{14}$

\section{Antigen Retrieval and Immunohistochemistry}

Formalin-fixed, paraffin-embedded, $5 \mu \mathrm{m}$ tissue sections were deparaffininzed in xylene and rehydrated with solutions of 100, 95 and $75 \%$ ethanol and deionized $\mathrm{H}_{2} \mathrm{O}$. Sections were placed in target retrieval solution (Dako, Carpenteria, CA, USA) and boiled in a Pascal pressure chamber (Dako) at $125^{\circ} \mathrm{C}$ for $30 \mathrm{~s}, 90^{\circ} \mathrm{C}$ for $10 \mathrm{~s}$, and then cooled to room temperature. Immunohistochemistry was performed using a two-step peroxidase method. Briefly, the sections were incubated with $1.4 \mu \mathrm{g} / \mathrm{ml}$ rabbit anti-survivin antibody (Cell Signaling, Danvers, MA, USA) or $0.5 \mu \mathrm{g} / \mathrm{ml}$ rabbit anti-TTK antibody (Sigma, St Louis, MO, USA) at $4{ }^{\circ} \mathrm{C}$ overnight and then incubated with 1:200 goat anti-rabbit IgG peroxidaseconjugated antibody (Vector Laboratories, Burlingame, CA, USA) or goat anti-rabbit IgG alkaline phosphatase-conjugated antibody (Vector laboratories) at room temperature for $1 \mathrm{~h}$. Immunoreactivity was then detected with NovaRed peroxidase substrate (Vector Laboratories) or vector AP red substrate (Vector Laboratories).

For quantification of survivin protein expression, the area of tumor corresponding to the highest survivin immunohistochemical staining was photographed at $\times 400$ magnification, and nuclear survivin expression was manually quantified in one such high-power field (typically $\sim 600$ cells). For quantification of TTK protein expression, a scale from $0-3+$ was used over the entire area of tumor present on the slide, with 0 corresponding to $<1 \%$ cytoplasmic staining, $1+1-$ $10 \%$ staining, $2+10-25 \%$ staining, and $3+>25 \%$ staining (Figure 2). Scores for each specimen were recorded (Table 3) and aggregate trends in the expression of immunoreactive protein before and after IPI treatment were depicted as the sum of individual samples multiplied times the score for each (Figure 2). $P$-values were calculated using an unpaired, twotailed Student's $t$-test in GraphPad Prism 5 for survivin expression or a two-tailed Fisher's exact test for TTK expression.

\section{RESULTS}

Overall, data from five pre-IPI tumor samples from unique patients and four post-IPI tumor samples (from three patients) permitted identification of 12 candidate genes that showed at least twofold differential expression based on normalized counts after IPI therapy $(P<0.01$, Table 2 and Figure 1). Benjamini-Hochberg $Q$-values were calculated for

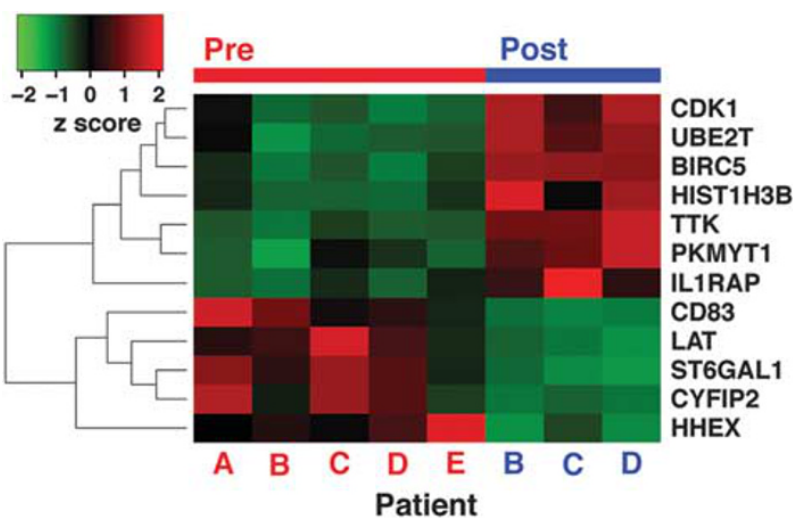

Figure 1 Heatmap of significantly altered gene expression levels by $Z$-score ( $>2.0$-fold, $P<0.01$ ) from NanoString PanCancer Pathways and PanCancer Immune gene panels. Red indicates an increase in expression, and green indicates a decrease in gene expression.

FDRs from 0.5 to 0.1 , leading to the identification of one gene, TTK, which was increased $\sim 3.1$-fold, and in which $P<Q$ at an FDR of $0.1(P=1.18 \mathrm{e}-4, Q=1.22 \mathrm{e}-4$; Figure 2$)$. Additionally, BIRC5, which encodes the protein survivin, was found to have $\sim 3.0$-fold higher expression after IPI at an FDR of $0.4(P=9.36 e-4, Q=9.76 e-4$; Figure 3$)$. $C D K 1$, which encodes a protein tyrosine kinase known to phosphorylate survivin, ${ }^{15,16}$ was also found to be significantly upregulated $(P=2.80 \mathrm{e}-3$; Figure 3$)$, although significant at an FDR of 0.5 (Table 2), additional evidence suggesting the importance of this pathway in resistance to an IPI-enhanced immune attack.

We confirmed tumor cell protein expression of TTK and survivin using immunohistochemistry in an expanded patient cohort, which included two patients treated with both IPI and nivolumab, an anti-PD-1 monoclonal antibody. Although our results were not statistically significant at $95 \%$ confidence $(P<0.05)$, likely due to differences in specimen treatment and fixation of these predominantly large resection specimens, we observed a relative increase in tumor cell TTK protein expression after IPI treatment $(P=0.0862$, Fisher's exact test; Figure 2 and Table 3). Additional immunohistochemical studies for survivin also confirmed expression in tumor cells as well as a relative increase on the protein level after IPI treatment $(P=0.1010$, Student's $t$-test; Figure 3$)$.

In addition to BIRC5, TTK, and CDK1, we identified a number of additional genes that may exhibit differential expression post-IPI in melanoma tumor cells (Figure 1 and Table 2), including UBE2T and HIST1H3B (both upregulated), as well as ST6GAL1 and HHEX (both downregulated). Two genes with $P<0.01$ were not significant at an FDR of 0.5 (Table 2). These included CYFIP2 (downregulated), which encodes a proapoptotic protein and a direct target of $\mathrm{p} 53,{ }^{17}$ and PKMYT1 (upregulated), which encodes the serine/ threonine kinase Myt1 and negatively regulates cell cycle G2/M transition through Cdc2. ${ }^{18}$ Several genes related to the immune response were also found to be differentially 
Table 2 List of genes with a significant change in expression $(P<0.01){ }^{*}$ before and after ipilimumab treatment with fold change and Benjamini-Hochberg analysis using FDRs of $0.5,0.4,0.3,0.2$, and 0.1 for $Q$-value calculation**

\begin{tabular}{|c|c|c|c|c|c|c|c|c|}
\hline \multirow[t]{2}{*}{$P$ rank } & \multirow[t]{2}{*}{ Gene name } & \multirow[t]{2}{*}{ Fold change } & \multirow{2}{*}{$\frac{\text { FDR }}{P}$} & \multirow{2}{*}{$\begin{array}{l}0.5 \\
Q\end{array}$} & \multirow{2}{*}{$\begin{array}{l}0.4 \\
Q\end{array}$} & \multirow{2}{*}{$\begin{array}{c}0.3 \\
Q\end{array}$} & \multirow{2}{*}{$\begin{array}{l}0.2 \\
Q\end{array}$} & \multirow{2}{*}{$\begin{array}{l}0.1 \\
Q\end{array}$} \\
\hline & & & & & & & & \\
\hline 1 & $\pi K$ & 3.12 & $1.18 e-04$ & $6.10 e-04$ & $4.88 e-04$ & $3.66 e-04$ & $2.44 e-04$ & $1.22 e-04$ \\
\hline 2 & BIRC5 & 3.01 & $9.36 e-04$ & $1.22 \mathrm{e}-03$ & $9.76 e-04$ & $7.32 e-04$ & $4.88 e-04$ & $2.44 e-04$ \\
\hline 3 & ST6GAL1 & -2.35 & $1.58 e-03$ & $1.83 e-03$ & $1.46 e-03$ & $1.10 \mathrm{e}-03$ & $7.32 e-04$ & $3.66 e-04$ \\
\hline 4 & CD83 & -3.29 & $1.77 e-03$ & $2.44 e-03$ & $1.95 e-03$ & $1.46 e-03$ & $9.76 e-04$ & $4.88 e-04$ \\
\hline 5 & CDK1 & 3.24 & $2.80 e-03$ & $3.05 e-03$ & $2.44 e-03$ & $1.83 e-03$ & $1.22 \mathrm{e}-03$ & $6.10 e-04$ \\
\hline 6 & LAT & -2.96 & $3.29 e-03$ & $3.66 e-03$ & $2.93 e-03$ & $2.20 e-03$ & $1.46 e-03$ & $7.32 e-04$ \\
\hline 7 & UBE2T & 2.25 & $3.94 e-03$ & $4.27 e-03$ & $3.41 e-03$ & $2.56 e-03$ & $1.71 e-03$ & $8.54 e-04$ \\
\hline 8 & HHEX & -2.52 & $4.66 e-03$ & $4.88 e-03$ & $3.90 e-03$ & $2.93 e-03$ & $1.95 e-03$ & $9.76 e-04$ \\
\hline 9 & HIST1H3B & 3.35 & $5.27 e-03$ & $5.49 e-03$ & $4.39 e-03$ & $3.29 e-03$ & $2.20 e-03$ & $1.10 e-03$ \\
\hline 10 & ILIRAP & 2.15 & $5.44 e-03$ & $6.10 e-03$ & $4.88 e-03$ & $3.66 e-03$ & $2.44 e-03$ & $1.22 e-03$ \\
\hline 11 & CYFIP2 & -3.63 & $8.05 e-03$ & $6.71 e-03$ & $5.37 e-03$ & $4.02 e-03$ & $2.68 e-03$ & $1.34 e-03$ \\
\hline 12 & PKMYT1 & 2.10 & $8.27 e-03$ & $7.32 e-03$ & $5.85 e-03$ & $4.39 e-03$ & $2.93 e-03$ & $1.46 e-03$ \\
\hline
\end{tabular}

* $P$-values were calculated using an unpaired, two-tailed Student's $t$-test on $\log _{2}$-transformed normalized counts.

** $Q$-values were determined using the method of Benjamini and Hochberg $(Q=i / n \times \mathrm{FDR}$, where $i$ is the $P$ rank, $n$ is the number of genes assayed, and FDR, false discovery rate). ${ }^{14}$

Bold values indicate significance at the corresponding FDR.

expressed at an FDR of 0.5, including IL1RAP (upregulated), CD83 (downregulated), and LAT (downregualted).

Differences in gene expression for several commonly encountered immune antigens, such as CD3, CD4, CD8, and CTLA4, were not statistically significant, likely reflecting the long length of time (average 323 days) between the last IPI dose and post-treatment biopsies when persistent immune responses are unlikely.

\section{DISCUSSION}

This preliminary study examines patients who were treated with IPI and had evidence of an autoimmune immunologic response, but were unable to mount a sustained effective antitumor effect, as determined by radiologic and clinical follow-up. Several patients did have an initial partial response to treatment and subsequently progressed, suggesting that the tumor cells may have become therapy-resistant despite evidence of an enhanced antihost cytotoxic response. Patients who develop autoimmune disorders as a result of IPI therapy and have archived pre- and post-treatment biopsies are uncommon, and thus our sample size is limited. Nonetheless, our data identify several genes that may be important in the changes that occur in melanoma tumor cells as a consequence of exposure to a highly activated immune environment. Within a set of 12 genes with a raw $P$-value of $<0.01$, we have identified two primary candidate genes, BIRC5 and TTK, that are transcriptionally upregulated within tumor cells after IPI therapy, suggesting a potential role of their respective protein in products in evasion of the host immune response elicited by IPI and thus potentially correlating with disease progression despite initial therapeutic responses in several of our patients. We further validated tumor cell expression of TTK and survivin proteins using immunohistochemistry, and showed a relative increase in both proteins after IPI treatment. In addition to BIRC5 and TTK, we have identified a set of eight additional genes that may be differentially expressed in metastatic melanomas after IPI treatment.

TTK encodes a dual-specificity protein tyrosine kinase (TTK, or MPS1) that is a known cell cycle regulator, specifically coordinating the spindle assembly checkpoint. ${ }^{19}$ During interphase, TTK is localized to the cytoplasm, but during mitosis, is also found at the kinetochore. ${ }^{19}$ TTK has an essential role in mitotic the spindle assembly checkpoint, recruiting other critical checkpoint proteins to the kinetochore. ${ }^{20,21}$ High levels of TTK are associated with aneuploidy, ${ }^{22}$ and high levels of TTK phosphorylation appear to dysregulate the spindle assembly checkpoint, as does impaired ubiquitination. ${ }^{23}$ Increased levels of TTK are thought to be supportive of aneuploidy, and reduction of TTK in cultured breast carcinoma cells using siRNA leads to aberrant mitoses and initiation of apoptosis pathways. ${ }^{24} \mathrm{~A}$ number of TTK-specific inhibitors, which appear to preferentially affect transformed cells, are in the early stages of clinical development, but like other ATP-competitive kinase inhibitors are likely vulnerable to resistance mutations. ${ }^{25}$

Survivin is an antiapoptotic protein that is widely expressed during development and in a broad range of human malignancies, but is found in low levels in normal, differ- 
a

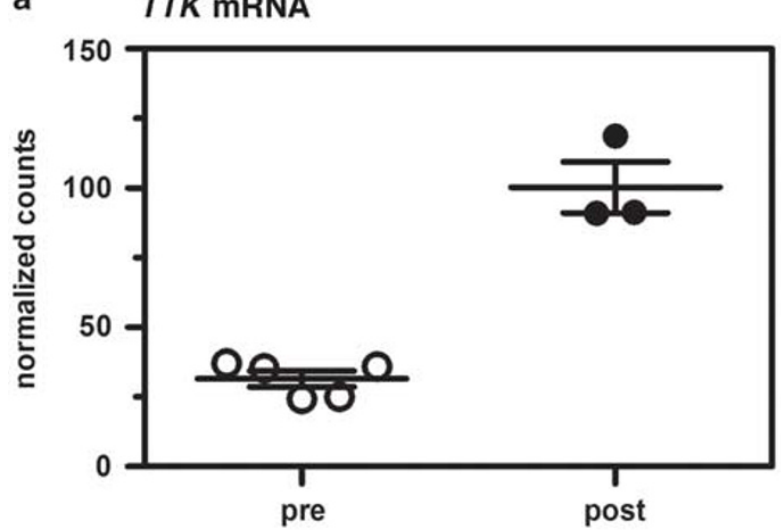

b

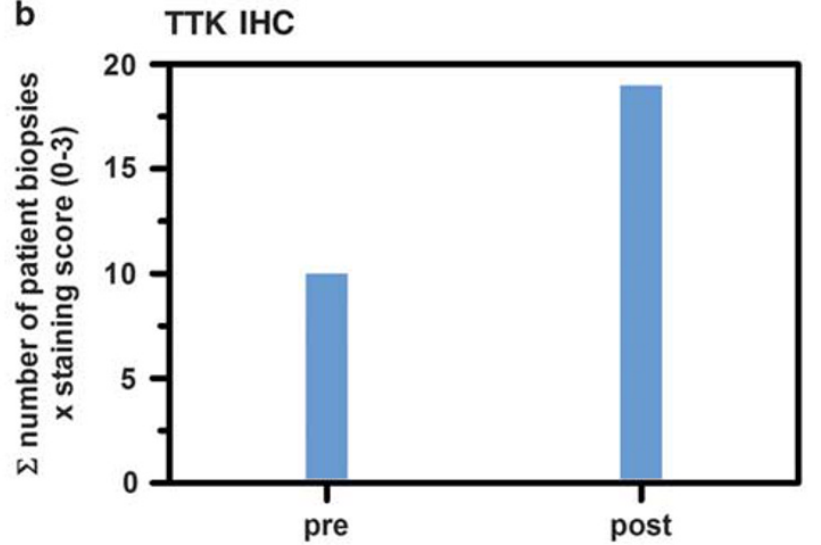

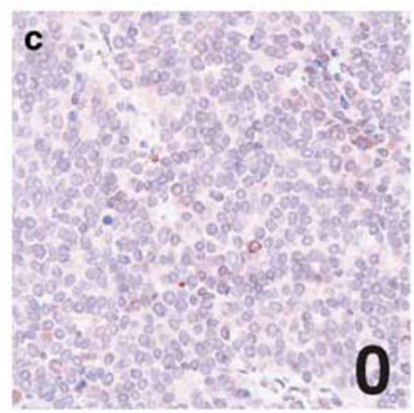
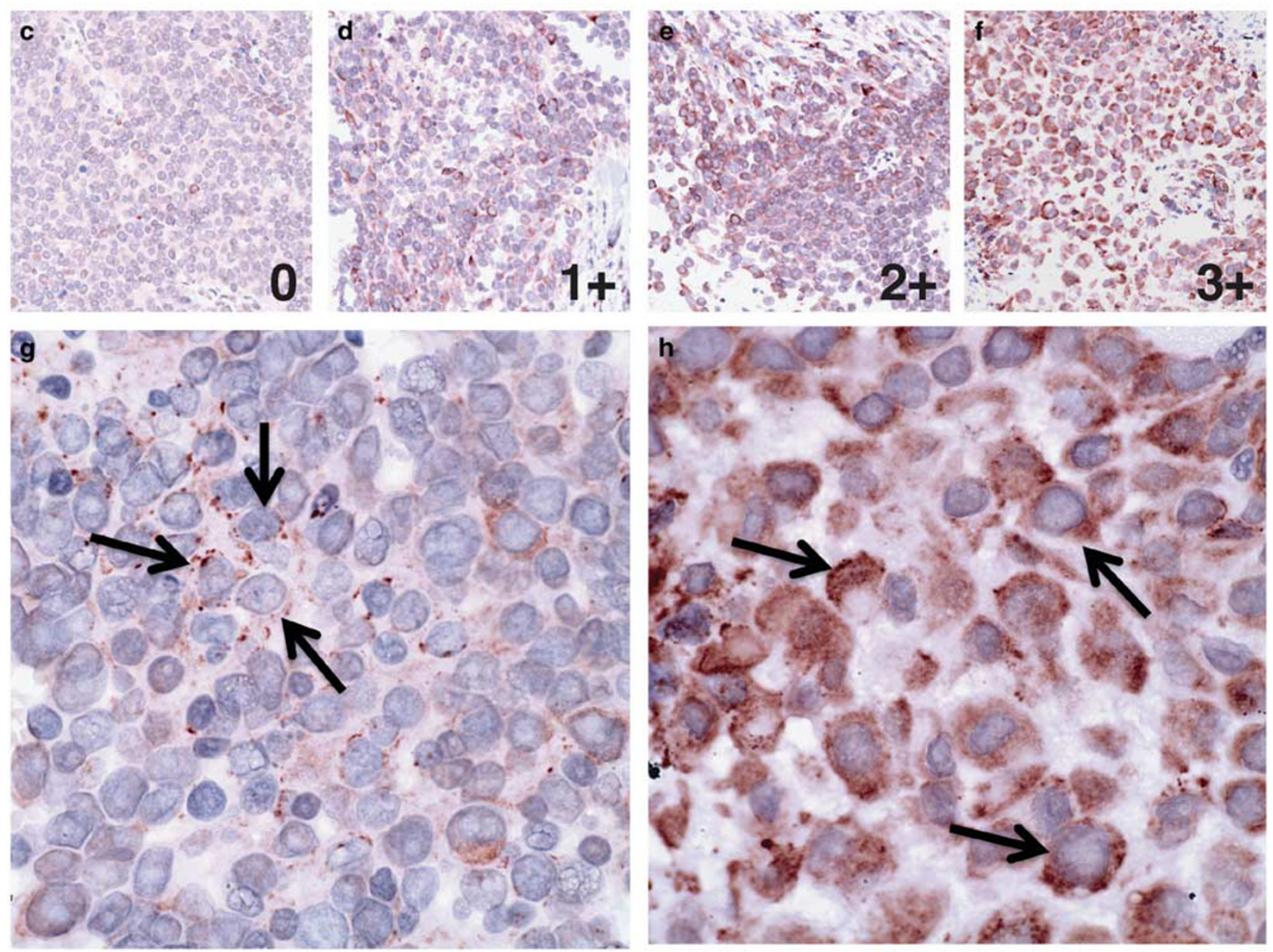

Figure 2 TTK (MPS1) expression after ipilimumab (IPI) treatment in patients with treatment-related autoimmune events on the mRNA and protein level. (a) Normalized TTK mRNA counts obtained from NanoString analysis before and after IPI $(P=1.18 \mathrm{e}-4$; mean \pm s.e.m., $n=5$ pre, $n=3$ after). (b) TTK immunohistochemical staining scores (0-3+) were multiplied by the number of cases with a given staining score and added together for pre- and postIPI totals. A relative increase in TKK expression is seen on the protein level $(P=0.0862$; see Table 3$)$. (c- $\mathbf{f})$ TTK immunohistochemical staining before and after IPI was quantified using the following $0-3+$ scale: (c) $0=<1 \%$, (d) $1+=1-10 \%$, (e) $2+=10-24 \%$, (f) $3+=>25 \%$ (see Table 3). (g) Low-level $\Pi$ TK expression (arrows) in which immunohistochemistry (IHC) staining is seen as sparse intracytoplasmic and perinuclear granules. (h) High-level cytoplasmic TTK protein expression (arrows) as seen more commonly in post-IPI specimens.

entiated cells. ${ }^{26,27}$ Additionally, survivin has been associated with prognosis and disease progression in melanoma, ${ }^{28-31}$ as well as numerous additional human malignancies including bladder, ${ }^{32}$ breast, ${ }^{33}$ lung, ${ }^{34}$ and gastric ${ }^{35}$ carcinoma. Furthermore, in bladder papillary urothelial carcinoma, survivin expression has been shown to be a better indicator of high- 
Table 3 TTK (MPS1) protein expression pre- and postipilimumab treatment in patients with treatment-related autoimmune events by immunohistochemistry $(P=0.0862$, Fisher's exact test).

\begin{tabular}{lcc}
\hline TTK expression & Pre & Post \\
\hline 0 & 1 & 0 \\
$1+$ & 2 & 0 \\
$2+$ & 4 & 5 \\
$3+$ & 0 & 3 \\
\hline
\end{tabular}

Scale of TTK expression: $0=<1 \%$ of cells, $1+=1-10 \%, 2+=10-24 \%$, $3+=>25 \%$ (see Figure 2 ).

grade histology and of recurrence than tumor Ki-67 index. ${ }^{36}$ In addition to its antiapoptotic role of suppressing caspases, ${ }^{37}$ survivin also appears to be necessary for chromosome alignment and segregation as a key component of the chromosomal passenger complex, playing a role in stimulating aurora B activity. ${ }^{38,39}$ Numerous studies have linked increased survivin expression in melanoma to poorer prognosis and have associated increased levels of survivin to disease progression from benign nevi to malignancy. ${ }^{28-31}$ Additionally, a study examining the expression of a panel of antiapoptotic proteins including survivin, livin, CIAP1, and CIAP2 in 52 primary cutaneous and 25 mucosal melanomas showed that nuclear expression of survivin was most correlated with poor prognosis among these biomarkers. ${ }^{31}$ Although survivin expression appeared to be related to Ki-67 proliferative index and was a better prognostic indicator, it was not correlated with clinical stage.

Similar to TTK, survivin is an attractive drug target, ${ }^{27,40,41}$ and a number of therapeutic agents targeting survivin are being developed, including both small molecules and mRNA antagonists. ${ }^{39,42}$ Additionally, survivin-specific $\mathrm{T}$ cells were recently shown to be correlated with clinical response in a survivin phase II trial. ${ }^{43}$ This is further evidence that survivin has an important role in melanoma tumor cell survival, and provides additional proof of concept for targeting survivin in melanoma patients. Although we were unable to correlate survivin-specific $\mathrm{T}$ cells with clinical response and the development of autoimmunity in our patients because of the retrospective nature of this study, this observation provides a potentially informative opportunity for further investigation.

Survivin expression has been observed in both the nuclear and cytoplasmic compartments. Nuclear staining is an independent prognostic indicator in non-small-cell lung carcinoma, ${ }^{34}$ whereas cytoplasmic expression (not nuclear expression) is prognostically important in gastric carcinoma. ${ }^{35}$ It is unclear if the specific subcellular localization of survivin protein expression has clinical significance. These observed differences may be due to the range of antibodies and immunohistochemical staining protocols used to quantify survivin expression, or may be due to differences in survivin function based on subcellular localization and cellular context. Cytoplasmic survivin, which is able to access mitochondria and bind caspases, is exported from the nucleus because of its nuclear export sequence through the nuclear export receptor Crm $1 .{ }^{44}$ Owing to its low molecular weight, survivin is able to diffuse passively across the nuclear membrane despite its lack of a nuclear localization sequence. ${ }^{44}$ Therefore, the cytoplasmic/nuclear survivin gradient and cellular context may have significance in its ability to conduct its dual functions of inhibition of apoptosis and as a regulator of the cell cycle. ${ }^{44}$ We observed primarily nuclear expression of survivin in all of our cases. However, we did observe many cells with cytoplasmic staining before treatment in one patient, with predominantly nuclear expression seen after treatment (Figure 3).

There are a number of possible biologic explanations for the clinical activity of IPI, which also may explain its undesirable autoimmune side effects. These include a shift in the balance of stimulatory and inhibitory cytotoxic T-cell receptors with specificity for self-antigens, or a decrease in the number or activity of CTLA4-positive regulatory $\mathrm{T}$ cells. We did not find significant changes in markers for cell populations that have previously been connected to IPI clinical activity ${ }^{8,9}$ (including the regulatory T-cell markers CD25 and FOXP3 and pan-T-cell markers CD3, CD4, and CD8) after IPI treatment. Although our study is not powered to detect subtle changes, the lack of significant expression differentials for these genes is perhaps due to the long length of time between the last IPI dose and post-treatment biopsy (average time 323 days in the original cohort) and the use of steroids to treat autoimmune complications in our patient cohort.

Although we did not find differential expression of immune genes previously connected to the clinical activity of IPI, we did find potentially significant differential expression of several other immune-related genes. IL1RAP (upregulated) is an interleukin 1 receptor accessory protein that regulates the inflammatory response to interleukins and is a possible prognostic marker in acute myeloid leukemia. ${ }^{45}$ This immune-related set also includes CD83 (downregulated), which encodes a transmembrane glycoprotein expressed on mature dendritic cells that has a stimulatory effect on the immune response, apparently through functions relating to antigen presentation. ${ }^{46}$ Interestingly, however, the soluble form of CD83 appears to have an inhibitory effect on the immune response by inhibiting monocyte differentiation into dendritic cells. ${ }^{47}$ Future studies resolving whether melanoma cells express higher levels of membrane-bound or secreted CD83 may therefore be informative. A third immune-related gene, LAT (downregulated), encodes a protein that is known to participate in $\mathrm{T}$-cell receptor signaling by acting as a docking site for $\mathrm{SH} 2$ domain-containing signaling molecules. ${ }^{48}$ Further study of 
a

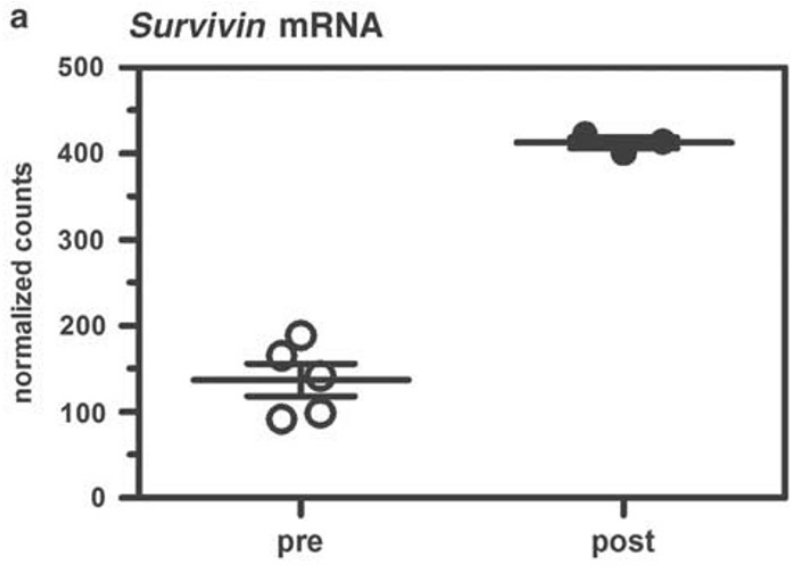

b

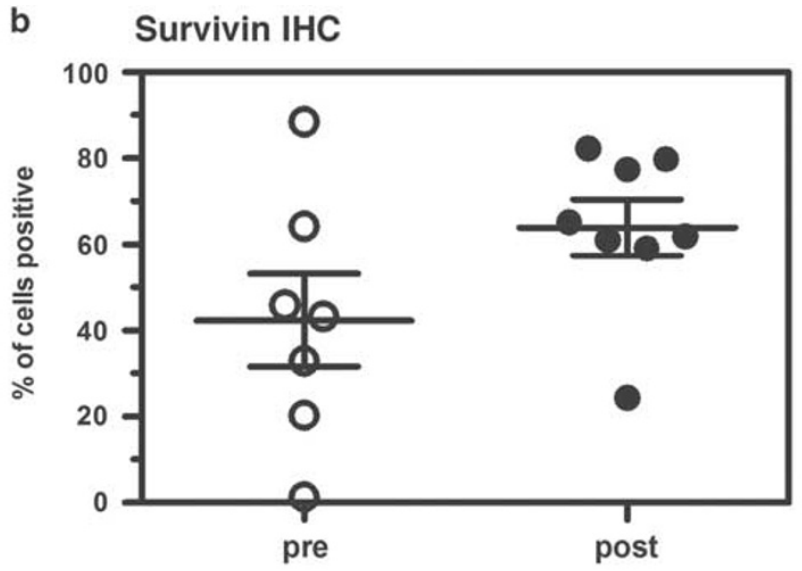

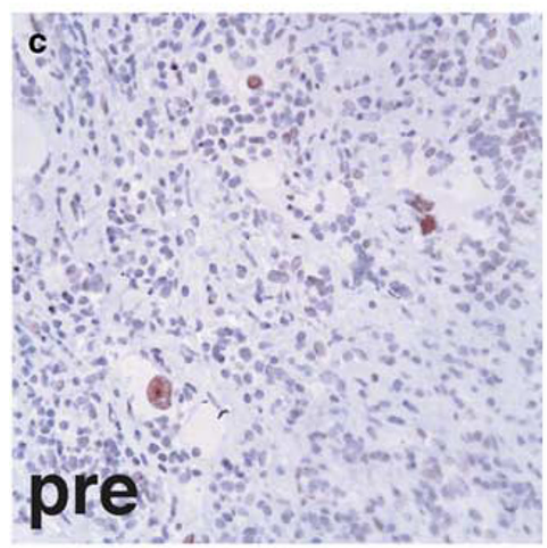
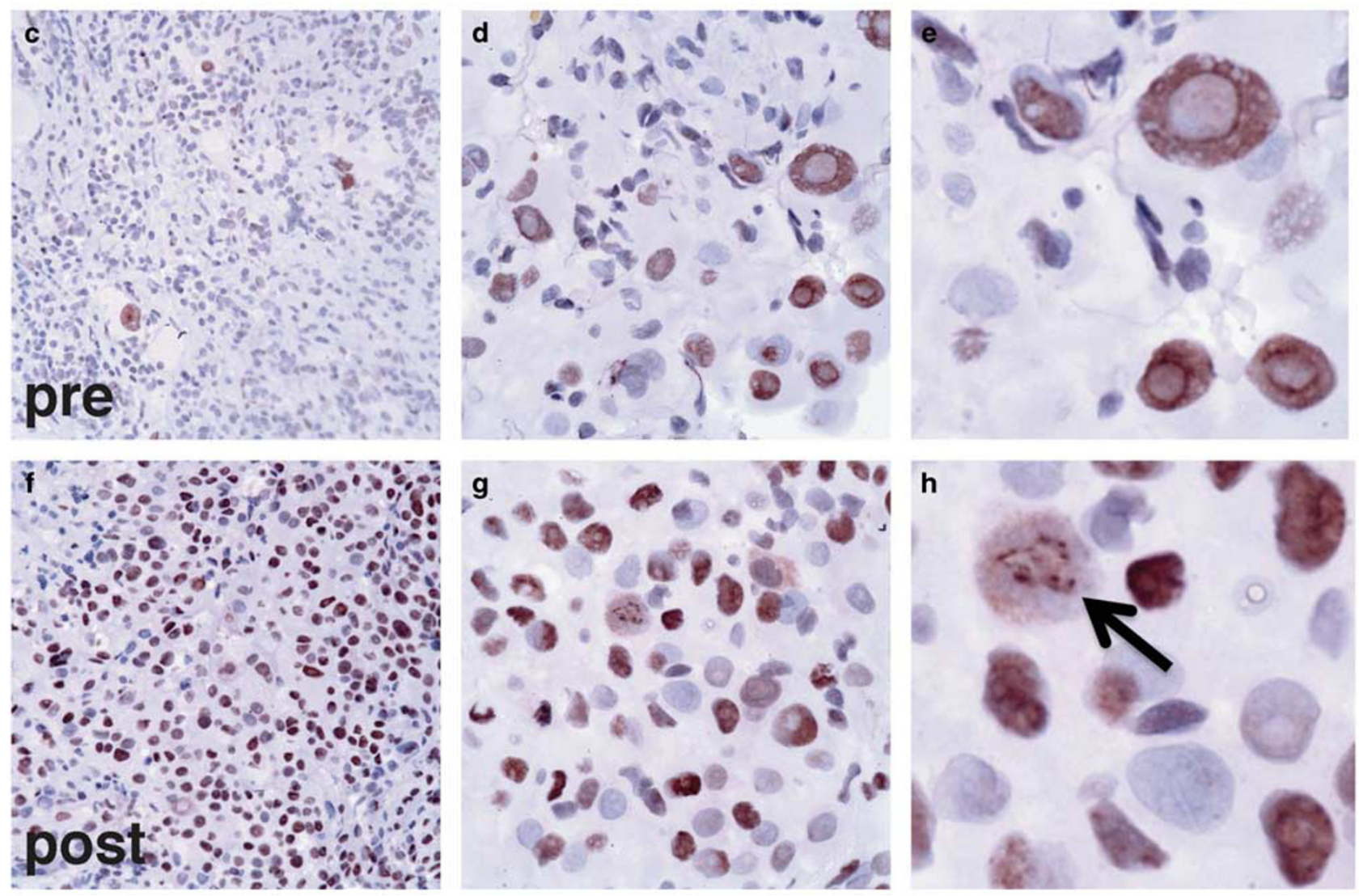

Figure 3 BIRC5 (survivin) expression after ipilimumab (IPI) treatment in patients with treatment-related autoimmune events on the mRNA and protein level. (a) Normalized BIRC5/survivin mRNA counts (mean \pm s.e.m., $n=5$ pre, $n=3$ after) obtained from NanoString analysis before and after IPI $(P=9.36$ e -4$)$. (b) Quantification of survivin immunohistochemical staining before and after IPI $(P=0.1010)$ using the expanded patient cohort (mean \pm s.e.m., $n=7$ pre, $n=8$ after). (c-h) Progressive magnifications (from left to right, $\times 200, \times 400, \times 1000$ ) of enhanced expression of survivin protein before (c-e) and after (f-h) IPI therapy in representative tumor from patient 3 (see Table 1). Before therapy, many cells exhibit cytoplasmic staining (c-e), whereas nearly every cell shows nuclear expression after treatment $(\mathbf{f}-\mathbf{h})$. Centromeric localization of survivin (arrow) can be seen in rare cells post-IPI (h).

LAT may therefore reveal important connections between this gene and IPI-related autoimmunity or the antitumor response.

Although the additional genes that were found to be differentially expressed (Figure 1) were significant only at an FDR of 0.5 (Table 2), our results may assist in future hypothesis generation. UBE2T (upregulated) encodes a E2 ubiquitin ligase involved in DNA damage repair and is known to ubiquitylate BRCA1 in breast carcinoma cells. ${ }^{49}$ HIST1H3B (upregulated) is commonly mutated in pediatric diffuse intrinsic pontine gliomas, ${ }^{50}$ and its differential expression in our study possibly suggests a change in the epigenetic 
landscape within melanoma tumor cells after IPI treatment. ST6GAL1 (downregulated) encodes a protein that catalyzes the transfer of sialic acid onto galactose-containing substrates, is aberrantly expressed in various epithelial cancers, and may affect cell invasion, motility, and apoptosis. ${ }^{51,52}$ Additionally, ST6GAL1 appears to have a role in the regulation of pleuripotency in human stem cells. ${ }^{51,53}$ HHEX (downregulated) encodes a homeobox transcription factor important in many areas of development, and has a possible role in the progression of hepatocellular carcinoma. ${ }^{54}$

This study is preliminary, as larger sample size, statistical validation, application of RECIST criteria, and lineage-specific analyses are necessary for confirmation. Examination of a cohort of patients who did not develop autoimmune disorders, and patients with autoimmune disorders who exhibited sustained treatment responses by their tumors for comparison are also required. However, these initial results for the first time identify several genes that may be significantly altered by the interaction between a highly activated, IPI-treated immune system and melanoma cells, including several that are involved in the immune response and have not been previously associated with IPI treatment. We confirmed this observation on the protein level with immunohistochemical analysis that localized TTK and survivin expression to the tumor cells. A preliminary finding of potential interest in this regard relates to apparent redistribution of cytoplasmic survivin to more exclusively nuclear localization as a consequence of IPI therapy in the setting of autoimmunity (Figure 3). Although the functional implications of survivin distribution in melanoma cells remains to be fully elucidated, ${ }^{55,56}$ this finding may warrant further investigation. With regard to the TTK pathway, our data suggest that upregulation in the expression of BIRC5 and TTK as may represent potential tumor responses to an IPIactivated immune system. An alternative hypothesis would be that pre-existing higher expression of BIRC5 and TTK in a subset of tumor cells could be protective against immune attack, leading to a selection advantage for these cells. Combination of immune checkpoint blockade agents, such as the coadministration of anti-CTLA4 and anti-PD-1 antibodies, may result in an unacceptably high occurrence of autoimmune complications. ${ }^{57}$ Our data instead suggest that combination therapy with an anti-survivin or anti-TTK agent with IPI or other checkpoint blockade agents may improve overall survival.

Supplementary Information accompanies the paper on the Laboratory Investigation website (http://www.laboratoryinvestigation.org)

\section{ACKNOWLEDGMENTS}

We thank Ronald Brown for technical assistance in performing NanoString experiments and Qian Zhan for technical assistance in performing immunohistochemistry. We also thank Brigham Research Institute for providing funding in the form of a BRI Microgrant.

\section{DISCLOSURE/CONFLICT OF INTEREST}

The authors declare no conflict of interest.
1. Leach DR, Krummel MF, Allison JP. Enhancement of antitumor immunity by CTLA-4 blockade. Science 1996;271:1734-1736.

2. Garber K. Industry makes strides in melanoma. Nat Biotechnol 2010;28: 763-764.

3. Hodi FS, O'Day SJ, McDermott DF, et al. Improved survival with ipilimumab in patients with metastatic melanoma. $\mathrm{N}$ Engl J Med 2010;363:711-723.

4. Sanderson K, Scotland R, Lee P, et al. Autoimmunity in a phase I trial of a fully human anti-cytotoxic T-lymphocyte antigen-4 monoclonal antibody with multiple melanoma peptides and Montanide ISA 51 for patients with resected stages III and IV melanoma. J Clin Oncol 2005;23:741-750.

5. Attia P, Phan GQ, Maker AV, et al. Autoimmunity correlates with tumor regression in patients with metastatic melanoma treated with anticytotoxic T-lymphocyte antigen-4. J Clin Oncol 2005;23:6043-6053.

6. Beck KE, Blansfield JA, Tran KQ, et al. Enterocolitis in patients with cancer after antibody blockade of cytotoxic T-lymphocyte-associated antigen 4. J Clin Oncol 2006;24:2283-2289.

7. Downey SG, Klapper JA, Smith FO, et al. Prognostic factors related to clinical response in patients with metastatic melanoma treated by CTLassociated antigen-4 blockade. Clin Cancer Res 2007;13:6681-6688.

8. Maker AV., Attia P, Rosenberg SA. Analysis of the cellular mechanism of antitumor responses and autoimmunity in patients treated with CTLA-4 blockade. J Immunol 2005;175:7746-7754.

9. Hamid O, Schmidt $H$, Nissan A, et al. A prospective phase II trial exploring the association between tumor microenvironment biomarkers and clinical activity of ipilimumab in advanced melanoma. J Transl Med 2011;9:204.

10. Hodi FS, Lawrence D, Lezcano C, et al. Bevacizumab plus ipilimumab in patients with metastatic melanoma. Cancer Immunol Res 2014;2: 632-642.

11. Klein O, Ebert LM, Nicholaou T, et al. Melan-A-specific cytotoxic T cells are associated with tumor regression and autoimmunity following treatment with anti-CTLA-4. Clin Cancer Res 2009;15:2507-2513.

12. Kulkarni MM. Digital multiplexed gene expression analysis using the NanoString nCounter System. Curr Protoc Mol Biol 2011;Chapter 25: Unit25B.10.

13. RStudio Team. RStudio: Integrated Development for R. RStudio Inc: Boston, MA, USA, 2015, available at http://www.rstudio.com/.

14. Benjamini $Y$, Hochberg Y. Controlling the false discovery rate: a practical and powerful approach to multiple testing. J R Stat Soc 1995;57:289-300.

15. O'Connor DS, Grossman D, Plescia J, et al. Regulation of apoptosis at cell division by p34cdc2 phosphorylation of survivin. Proc Natl Acad Sci USA 2000;97:13103-13107.

16. Goga A, Yang D, Tward AD, et al. Inhibition of CDK1 as a potential therapy for tumors over-expressing MYC. Nat Med 2007;13:820-827.

17. Mongroo PS, Noubissi FK, Cuatrecasas M, et al. IMP-1 displays cross-talk with K-Ras and modulates colon cancer cell survival through the novel proapoptotic protein CYFIP2. Cancer Res 2011;71:2172-2182.

18. Wells NJ, Watanabe N, Tokusumi T, et al. The C-terminal domain of the Cdc2 inhibitory kinase Myt1 interacts with Cdc2 complexes and is required for inhibition of $\mathrm{G}(2) / \mathrm{M}$ progression. J Cell Sci 1999;112: 3361-3371.

19. Liu X, Winey M. The MPS1 family of protein kinases. Annu Rev Biochem 2014;81:561-585.

20. Abrieu A, Magnaghi-Jaulin L, Kahana JA, et al. Mps1 is a kinetochoreassociated kinase essential for the vertebrate mitotic checkpoint. Cell 2001;106:83-93.

21. Hardwick KG, Weiss E, Luca FC, et al. Activation of the budding yeast spindle assembly checkpoint without mitotic spindle disruption. Science 1996;273:953-956.

22. Ling $Y$, Zhang $X$, Bai $Y$, et al. Overexpression of Mps1 in colon cancer cells attenuates the spindle assembly checkpoint and increases aneuploidy. Biochem Biophys Res Commun 2014;450:1690-1695.

23. Liu J, Cheng X, Zhang Y, et al. Phosphorylation of Mps 1 by BRAFV600E prevents Mps1 degradation and contributes to chromosome instability in melanoma. Oncogene 2013;32:713-723.

24. Daniel J, Coulter J, Woo J, et al. High levels of the Mps1 checkpoint protein are protective of aneuploidy in breast cancer cells. Proc Natl Acad Sci USA 2011;108:5384-5389.

25. Koch A, Maia A, Janssen $A$, et al. Molecular basis underlying resistance to Mps1/TTK inhibitors. Oncogene 2015; 1-11. 
26. Ambrosini G, Adida C, Altieri DC. A novel anti-apoptosis gene, survivin, expressed in cancer and lymphoma. Nat Med 1997;3:917-921.

27. Ryan BM, O'Donovan N, Duffy MJ. Survivin: a new target for anti-cancer therapy. Cancer Treat Rev 2009;35:553-562.

28. Takeuchi H, Morton DL, Elashoff $D$, et al. Survivin expression by metastatic melanoma predicts poor disease outcome in patients receiving adjuvant polyvalent vaccine. Int J Cancer 2005;117:1032-1038.

29. Gradilone A, Gazzaniga P, Ribuffo D, et al. Survivin, bcl-2, bax, and bcl-X gene expression in sentinel lymph nodes from melanoma patients. $\mathrm{J}$ Clin Oncol 2003:21:306-312.

30. Alonso SR, Ortiz P, Pollán M, et al. Progression in cutaneous malignant melanoma is associated with distinct expression profiles. Am J Pathol 2004;164:193-203.

31. Chen N, Gong J, Chen X, et al. Caspases and inhibitor of apoptosis proteins in cutaneous and mucosal melanoma: expression profile and clinicopathologic significance. Hum Pathol 2009;40:950-956.

32. Jeon C, Kim M, Kwak C, et al. Prognostic role of survivin in bladder cancer: a systematic review and meta-analysis. PLoS One 2013;8: e76719.

33. Song J, Su H, Zhou Y, et al. Prognostic value of survivin expression in breast cancer patients: a meta-analysis. Tumour Biol 2013;34: 2053-2062.

34. Shinohara ET, Gonzalez A, Massion PP, et al. Nuclear survivin predicts recurrence and poor survival in patients with resected nonsmall cell lung carcinoma. Cancer 2005;103:1685-1692.

35. Liu JL, Gao W, Kang QM, et al. Prognostic value of survivin in patients with gastric cancer: a systematic review with meta-analysis. PLoS One 2013;8:1-9.

36. Chen YB, Tu JJ, Kao J, et al. Survivin as a useful adjunct marker for the grading of papillary urothelial carcinoma. Arch Pathol Lab Med 2008;132:224-231.

37. Shin S, Sung BJ, Cho YS, et al. An anti-apoptotic protein human survivin is a direct inhibitor of caspase-3 and -7. Biochemistry 2001;40: 1117-1123.

38. Bolton $\mathrm{M}$, Lan W, Powers $\mathrm{S}$, et al. Aurora B kinase exists in a complex with survivin and INCENP and its kinase activity is stimulated by survivin binding and phosphorylation. Mol Biol Cell 2003;13: 3064-3077.

39. Coumar MS, Tsai FY, Kanwar JR, et al. Treat cancers by targeting survivin: just a dream or future reality? Cancer Treat Rev 2013;39: 802-811.

40. Pennati M, Folini M, Zaffaroni N. Targeting survivin in cancer therapy: fulfilled promises and open questions. Carcinogenesis 2007;28: 1133-1139.

41. Singh N, Krishnakumar S, Kanwar RK, et al. Clinical aspects for survivin: a crucial molecule for targeting drug-resistant cancers. Drug Discov Today 2014;20:578-587.

42. Raetz EA, Morrison D, Romanos-Sirakis E, et al. A phase I study of EZN-3042, a novel survivin messenger ribonucleic acid (mRNA) antagonist, administered in combination with chemotherapy in children with relapsed acute lymphoblastic leukemia (ALL): a report from the therapeutic advances in childhood leu. J Pediatr Hematol Oncol 2014;36:458-463.

43. Becker JC, Andersen MH, Hofmeister-Mü ller V, et al. Survivin-specific T-cell reactivity correlates with tumor response and patient survival: $A$ phase-II peptide vaccination trial in metastatic melanoma. Cancer Immunol Immunother 2012;61:2091-2103.

44. Stauber RH, Mann W, Knauer SK. Nuclear and cytoplasmic survivin: molecular mechanism, prognostic, and therapeutic potential. Cancer Res 2007;67:5999-6002.

45. Barreyro L, Will B, Bartholdy B, et al. Overexpression of IL-1 receptor accessory protein in stem and progenitor cells and outcome correlation in AML and MDS. Blood 2012;120:1290-1298.

46. Cao W, Lee SH, Lu J. CD83 is preformed inside monocytes, macrophages and dendritic cells, but it is only stably expressed on activated dendritic cells. Biochem J 2005;385:85-93.

47. Lin $\mathrm{H}$, Liang $\mathrm{S}$, Zhong Z, et al. Soluble CD83 inhibits human monocyte differentiation into dendritic cells in vitro. Cell Immunol 2014;292: 25-31.

48. Horejsi V. Transmembrane adaptor proteins in membrane microdomains: Important regulators of immunoreceptor signaling. Immunol Lett 2004;92:43-49.

49. Ueki T, Park JH, Nishidate T, et al. Ubiquitination and downregulation of BRCA1 by ubiquitin-conjugating enzyme E2T overexpression in human breast cancer cells. Cancer Res 2009;69:8752-8760.

50. Wu G, Broniscer A, McEachron TA, et al. Somatic histone H3 alterations in pediatric diffuse intrinsic pontine gliomas and non-brainstem glioblastomas. Nat Genet 2012;44:251-253.

51. Swindall AF, Londono-Joshi Al, Schultz MJ, et al. ST6Gal-I protein expression is upregulated in human epithelial tumors and correlates with stem cell markers in normal tissues and colon cancer cell lines. Cancer Res 2013;73:2368-2378.

52. Zhuo Y, Bellis SL. Emerging role of alpha2,6-sialic acid as a negative regulator of galectin binding and function. J Biol Chem 2011;286: 5935-5941.

53. Wang YC, Stein JW, Lynch CL, et al. Glycosyltransferase ST6GAL1 contributes to the regulation of pluripotency in human pluripotent stem cells. Sci Rep 2015; 5.

54. Su J, You P, Zhao JP, et al. A potential role for the homeoprotein Hhex in hepatocellular carcinoma progression. Med Oncol 2012;29: 1059-1067.

55. Garg H, Suri P, Gupta JC, et al. Survivin: a unique target for tumor therapy. Cancer Cell Int 2016;16:49.

56. Li F, Yang J, Ramnath N, et al. Nuclear or cytoplasmic expression of survivin: What is the significance? Int J Cancer 2005;114:509-512.

57. Haanen JB, Thienen Hv, Blank CU. Toxicity patterns with immunomodulating antibodies and their combinations. Semin Oncol 2015;42:423-428. 